\title{
Introduction: a new stage in the fight against the HIV/AIDS pandemic - an economic perspective
}

\section{Benjamin Coriat}

For the actors involved in the fight against AIDS, as well as for observers and analysts, it is now clear that with the new millennium we also entered a new stage in the fight against AIDS. In many aspects - and often decisive ones - we are facing an entirely new situation.

To put it succinctly: while the core issue, after the development of the first tritherapies (in 1996-97), still revolved around the question of whether these drugs could be considered cost-effective enough to be recommended for treating patients in the southern countries, ${ }^{1}$ now the central issue is the extension of universal and free access on a global scale. Admittedly, we are still very far from establishing all the necessary conditions to attain this objective, but the important thing is that this objective has been defined and adopted. After many initiatives and debates, ${ }^{2}$ the decisive step was taken in 2006. In June of that year, on the occasion of the General Assembly HighLevel Meeting on HIV/AIDS, the WHO member states made a joint declaration wherein they set the objective of promoting universal access by 2010. The G8 summit at Gleneagles, following on from previous declarations and commitments, went even further. If universal access was to be achieved by 2010 , it would have to be 'free of charge'. ${ }^{3}$

A few figures may help us to appreciate the scale of the challenge taken on by the community of actors engaged in the fight against AIDS. According to the latest progress report published under the auspices of the WHO, UNAIDS and UNICEF, only about 2,015,000 people living with HIV/AIDS (PLWHA) are currently receiving treatment in low- and middle-income countries. This represents 28 per cent coverage of the 7.1 million people in urgent need (WHO, UNAIDS, UNICEF, 2007). This coverage rate of 28 per cent may appear fairly honourable, until we measure the scale of the problem. For instance, some 1.6 million people died of AIDS last year in Sub-Saharan Africa alone. And although the rate of expansion of the epidemic appears to be slowing, it has nevertheless been 
estimated that 2.5 million new people were infected during 2007 (UNAIDS, WHO, 2007) ${ }^{4}$ This gives us a better idea of the huge undertaking represented by the objective of universal (and free) access by 2010 .

Still, whatever the scale and complexity of the task, the target has now been set, and it was certainly time this was done. In this 'forced march' on which we are embarking, what is the point of departure, and how far have we advanced? What resources can we rely on, and what are the main obstacles we face? This book sets out to tackle these questions, and this means we must also endeavour clearly to define the new situation that has emerged. We wish to highlight both the hopes it represents - because universal free access for all PLWHA is now on the agenda - and the difficulties that remain to be overcome. This challenge can only be faced by advancing with our eyes wide open, by naming the problems and being prepared to confront them. Based on the findings of researchers working on socio-economic programmes initiated and supported by the ANRS, this book is intended to contribute to a state-of-the art review of the knowledge acquired in the fight against AIDS, from which further advances can be made. ${ }^{5}$

From this perspective, and without any claim to be exhaustive, simply to facilitate the reading of the chapters presented in this book - each of which makes its own particular contribution - the next few pages will give an account of some of the essential changes of the last decade. To go straight to the heart of the matter, we shall concentrate on three aspects of these changes: the mobilization of financial resources enabling access to treatment, the price and variety of drugs effectively available in the south, and the legal framework governing the circulation of the drugs needed to fight the pandemic. Admittedly, these three issues are far from covering all the dimensions involved in the spread of the epidemic and the fight to control it. However, insofar as they attach prime importance to the interplay of actors and interests now emerging in the south in the fight against the pandemic, we believe that they are emblematic of the current political economy of AIDS in these countries.

\section{FINANCE: THE COMMITMENT OF THE 'BIG THREE' AND THE STRONG RISE IN THE SUPPLY OF FUNDING}

The most spectacular changes to mark the new decade have certainly been those on the financial level. Up until the end of the 1990s, the financial resources available for the provision of care to patients in the south were rare and parsimonious (in 1996, only about $\$ 300$ million were spent). The growth in funding in the 2000s, and its recent acceleration, has totally 
transformed the landscape, with the successive introduction of three major initiatives, of very different scope and nature.

In 2000, the World Bank, an important provider of resources in the field of public health, reorganized its programmes to create a new tool, the Multi-Country HIV/AIDS Program (MAP), better designed and targeted than earlier initiatives, though not without certain complexities. This first change was followed by two other major initiatives of very different natures, which completed a revolution in the landscape. The first was the creation of the Global Fund against Tuberculosis, AIDS and Malaria (GFTAM). A multilateral organization, largely based on public aid, the GFTAM rapidly established itself as a key instrument in the fight against AIDS. Its intervention was to transform the situation.

Soon afterwards, in 2004, another large-scale initiative emerged, from the United States, with the launching of the President's Emergency Plan for AIDS Relief (Pepfar). This is a 'national' initiative, characterized in particular by the control of the US president and his administration over the distribution of funds. However, by its very size (a budget of US\$15 billion for the five-year period 2004-08), the launching of the Pepfar confirms the idea that we have entered a new era.

A brief presentation of each of these three initiatives will allow us to begin to understand the new environment in which the actors in the fight against AIDS are now operating.

\section{The World Bank MAP}

It was in the year 2000 that the World Bank, long active in the field of public health in southern countries, reorganized its programmes to create the Multi Country AIDS Program. The objective was to encourage the scalingup of initiatives by offering additional resources to countries prepared to commit themselves to the fight against AIDS. Funds are allocated as a grant or credit (that is, loan); and several mechanisms can be used, according to the nature of the loans and the specific programmes implemented within the frame of the MAP.

To benefit from these funds, a country must institute a high-level HIV/AIDS coordinating body, within which, amongst other conditions, the main stakeholders concerned in the fight against the disease must be well represented. This coordinating body, the National AIDS Council (NAC) or its secretariat, is the interlocutor of the World Bank, receiving the funds and accounting for their use. Over the period 2001-05, the MAP allocated US\$1.2 billion, to which we can add US\$0.5 billion from other sources within the World Bank, making a total contribution of US\$1.7 billion (Bernstein and Sessions, 2007). 
The importance of the World Bank's action lies above all in the fact that the funds allocated are destined first and foremost for the improvement of national health systems, generally sorely lacking in the countries concerned. And in the future it is also in this domain, where it has the most expertise, that the World Bank is called on to concentrate its efforts (Bernstein and Sessions, 2007).

\section{The Global Fund}

Without a doubt, the establishment of this institution constitutes the single most important event of the 2000s in the fight against AIDS, and we shall therefore dwell on it for a moment. The GFTAM (hereafter the Global Fund), was created in 2002 (the first grants were made in March 2002) following discussions initiated notably during the G8 heads of state meeting in Okinawa.

The Global Fund is structured around a highly original funding mechanism. Apart from the fact that it is founded on the principle of multilateralism (associating, in its governance system, countries from north and south, NGOs and representatives of the private sector), one of the distinctive features of the Global Fund is that, unlike many other donors, it has adopted a model that provides funding to country governments and in-country stakeholders based solely on proposals and implementation plans designed by the countries themselves. What is more, unlike the World Bank (and, as we shall see below, the Pepfar), the Global Fund is a pure financing instrument, not an implementing agency. On the basis of explicitly defined criteria, its action is aimed at low- and middle-income countries, for the three diseases (AIDS, tuberculosis and malaria) responsible for the most devastating epidemics among southern populations. Any country that meets the criteria clearly defined in the Global Fund's charter and whose proposal is approved by the experts of the Technical Review Panel (TRP), ${ }^{6}$ is allocated the funds requested in the programme project submitted during one of the 'rounds' through which the Global Fund calls for proposals.

The Global Fund is not represented in southern countries. Like the World Bank, its actions are implemented through structures that are specially created when countries submit their requests for funds. These structures are Principal Recipients (PR) and Local Fund Agents (LFAs), who operate within the frame of Country Coordinating Mechanisms (CCMs), established to receive the funds and implement the programmes. These CCMs are made up of representatives from governments, multilateral and bilateral donors, NGOs, academic institutions, private sector representatives and people living with the diseases. 
Table I.1 Distribution of GFTAM grant portfolio, rounds 1-6, by region, disease and country income (percentage)

\begin{tabular}{llrlll}
\hline By region & By disease & By country income \\
\hline 55 & Sub-Saharan Africa & 58 & HIV/AIDS & 67 & Low income \\
16 & East Asia \& Pacific & 24 & Malaria & 25 & $\begin{array}{c}\text { Lower-middle } \\
\text { income }\end{array}$ \\
10 & Latin American \& Caribbean & 17 & Tuberculosis \\
10 & Eastern Europe \& Central Asia & 1 & $\begin{array}{l}\text { Health systems } \\
\text { strengthening }\end{array}$ & 8 & $\begin{array}{l}\text { Upper-middle } \\
\text { income }\end{array}$ \\
& South Asia & & & & \\
5 & Middle East \& North Africa & & & & \\
\hline
\end{tabular}

Source: 'Monthly Progress Update - 31 October, 2007' available at www.theglobalfund.org.

The CCM is responsible for designing the plan for the fight against AIDS and then drawing up the corresponding document to be submitted to the GFTAM, where the TRP makes its evaluation. The proposal submitted to the TRP for assessment may cover several different aspects, including prevention, care and treatment. The request must satisfy fairly strict criteria of efficiency and transparency. If accepted, it is funded as it stands (or subject to clarification and minor modifications). If it is rejected by the TRP, it can be improved or clarified and re-submitted during a subsequent round. The general view is that the long and complex process of drawing up this 'application', often requiring advice from outside experts, is a demanding exercise for the participants, but highly enriching, arming them to face the difficulties that any plan of this nature necessarily encounters during its implementation. It is one of the Global Fund's ambitions to establish itself as a provider of funds for 'locally-driven strategies'.

The resources made available to the CCMs contain two 'flexibilities' particularly appreciated by the recipient countries. Fund commitments are pluriannual, providing assurance of continuity in actions and treatments. Once it has been approved, moreover, the budget is allocated in advance, enabling the operators to act and plan with a certain peace of mind about the future.

The growth in the Global Fund's activity has been spectacular. At the end of 2007, ‘. . the Global Fund has approved a total of US\$8.7 billion to more than 450 grants in 136 countries. Of the US\$8.7 billion approved, US\$4.6 billion has been disbursed to public and private recipients in 134 countries; and 98 percent of approved grants have signed grant agreements'. ${ }^{7}$ The distribution of the grant portfolio, based on approved grant amounts for rounds 1 through $6,{ }^{8}$ is given in Table I. 1 . 
Table I.2 Distribution of GFTAM grant portfolio, rounds 2-6, by expenditure and implementing entity (percentage)

\begin{tabular}{llcc}
\hline By type of expenditure & \multicolumn{2}{c}{ By implementing entity } \\
\hline 48 & Commodities, products \& drugs & 51 & $\begin{array}{l}\text { Government } \\
\text { Non-governmental \& } \\
\text { community-based } \\
\text { organizations }\end{array}$ \\
11 & Human resources & 24 & $\begin{array}{c}\text { Faith-based } \\
\text { organizations }\end{array}$ \\
11 & Administration & 5 & $\begin{array}{l}\text { Private sector } \\
\text { Infrastructure \& equipment }\end{array}$ \\
2 & Monitoring \& evaluation & 6 & $\begin{array}{c}\text { Communities living with } \\
\text { the diseases }\end{array}$ \\
6 & Other & 5 & Other \\
\hline
\end{tabular}

Source: 'Monthly Progress Update - 31 October 2007', available at www.theglobalfund.org.

The grant portfolio can also be broken down by type of expenditure and by type of implementing entity (Table I.2). (This analysis is based on the two-year budget amounts originally submitted in the grant proposals for rounds 2 through 6.)

Finally, as far as HIV alone is concerned, up until mid-2007, some 1.1 million PLWHA have been included in treatments funded by the Global Fund.

These results have only been achieved through the strong mobilization of donors. To date, a total of US\$17.8 billion has been pledged and/or contributed through 2010 to the Global Fund. Current figures are given in Table 1.3.

\section{The President's Emergency Plan for AIDS Relief}

The most recent of the three initiatives, this is also the most powerful instrument, in terms of the amount of money committed, and the most singular, in terms of its governing principles.

Launched in fiscal year 2004, Pepfar is a five-year, $\$ 15$ billion national programme. It is intended to provide concentrated assistance to 15 countries affected by HIV/AIDS and moderate assistance to more than 100 other countries. This explains why several sources of funding exist in many countries, combining funds from the Pepfar, the World Bank and the GFTAM. As we shall see, this can pose certain problems, as the principles 


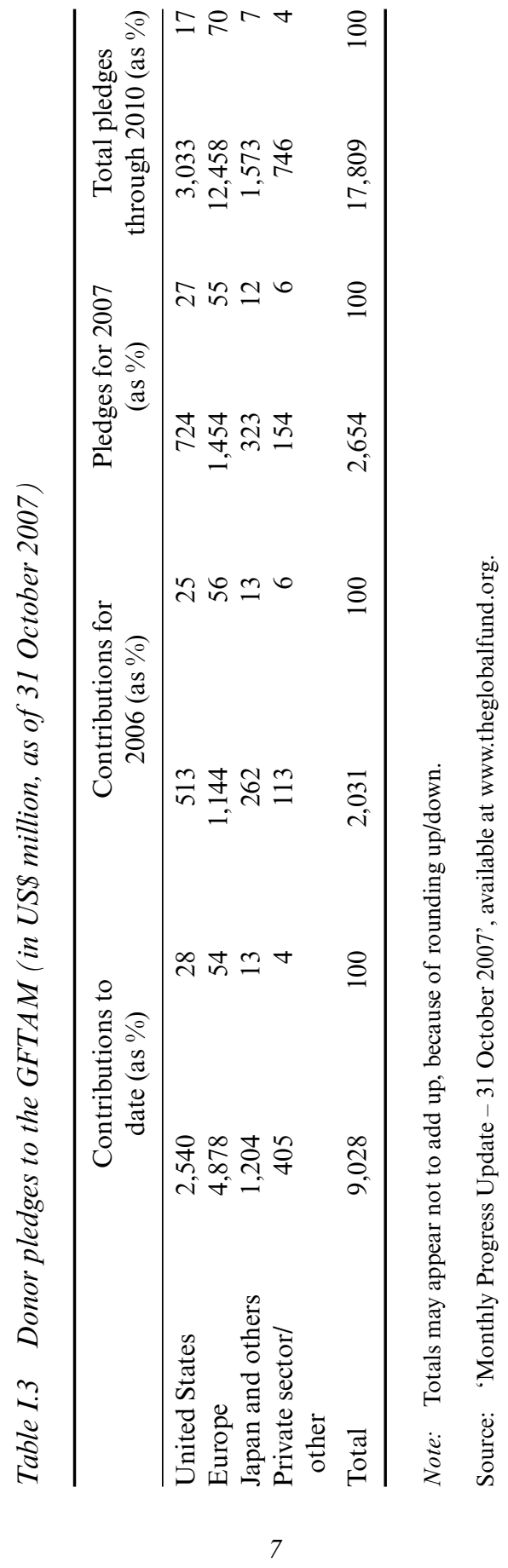


governing the allocation of funds and the associated constraints differ from one institution to another. ${ }^{9}$

The organization of Pepfar is complicated, involving several different levels and institutions of the American administration. The executive arm of the Pepfar is the independent federal government agency USAID, present in many of the southern countries to which funds are allocated. Pepfar's funds are paid by the US Treasury, year by year, within the frame of the annual budget vote, prohibiting advances in excess of the annual allocations.

To benefit from these funds, recipient organizations must previously have been qualified. This process of qualification is designed in such a way that in practice, it 'tends to favour recipient organizations with considerable existing capacity and a long history of working with US Government agencies' (Bernstein and Sessions, 2007).

Last but not least, the Pepfar's institutions and partners are obliged, when they purchase drugs, to respect certain rules that favour the purchase of patented and/or FDA-approved drugs, with the result that the prices they pay are rarely the most favourable on the market. Thus, in the key findings of its assessment of the Pepfar, published in 2005, the US General Accounting Office (now the Government Accountability Office - GAO) observed that: 'The Emergency Plan's selection of ARV products results in higher prices for most of the first line regimens. At the price quoted to us during June and July 2004, the differences in price between the original version of an ARV provided under the Emergency Plan and the lowestversion of an $A R V$ provided under the other initiatives ranged from $\$ 11$ less per person year to $\$ 328$ more for the original version.'

The GAO experts concluded with this point: 'For every 100,000 patients on WHO's first choice regimen for 5 years, the plan could pay over $\$ 170$ million more than other initiatives to purchase the ARVs' (US Government Accountability Office, 2005, p. 5). All in all, although the sum total of available resources still falls far short of that needed to ensure access to treatment for every person in need, the current situation is no longer characterized by the dearth in resources that could be observed in the second half of the 1990s. ${ }^{10}$

The mass of funds available even raises new questions for those involved in the fight against the pandemic. In many cases, it is no longer the absence of financial resources but the limits imposed by the degraded state of public health systems that constitute the biggest obstacles to progress in providing access to care. And even if initiatives are currently under way to favour the introduction of more efficient, less labour-intensive methods of caring for patients, there is still a long way to go. ${ }^{11}$ 


\section{THE PRICE, VARIETY AND AVAILABILITY OF MEDICATIONS}

The other radical transformation concerns the evolution in the 'market' for drugs. To be more accurate, this involves a succession of changes, the combined effects of which have ended up creating an entirely different situation in the 2000 s to that which prevailed in the previous decade.

\section{A Spectacular Fall in the Price of First-line ARVs}

The first and almost certainly the most important change was the large fall in the prices of first-line treatments. ${ }^{12}$ For the simplest combinations which are also the most widely used in southern countries - the fall in prices was indeed spectacular. At the end of the 1990s, a patented tritherapy was put on the market at a price of about $\$ 12-14,000$ dollars per person per year. They are now available (for the simplest, most common formulations) at a price of about $\$ 100$ per person per year.

Several factors have combined to produce this spectacular price reduction. The trend was initiated by Brazil, which embarked on the production of generic ARVs at a very early stage, in its national laboratory Farmanguinos. But the fall in price only really took on its full dimensions when Asian generic producers - Thai, but above all Indian, the latter rapidly becoming the 'pharmacy of the Third World' - resolutely decided to offer their products on the world market. Under the spur of competition and reciprocal imitation, prices collapsed. The Indian laboratory Cipla performed the remarkable exploit of bringing onto the market a fixed-dose tritherapy (Triomune) at a very low price. ${ }^{13}$ This innovation was only possible because Cipla (using the opportunity provided by Indian IP law prevailing until 2005) was able to aggregate, in a single pill, three ARVs patented (in developed countries) by different companies. This resulted in dramatic price reductions. The type of combination of drugs offered in this first-line fixed-dose triple therapy is available today for as little as US\$132 per patient per year and constitutes the most widespread first-line treatment in many DCs.

This downward trend was all the more powerful and sustained because some of the big suppliers of brand-name ARVs also participated in it, in their own way, by launching a joint programme with certain international organizations for the distribution of patented drugs at preferential prices for southern countries. Although there is no doubt that this initiative called the 'ACCESS program'14 - helped to relieve the pressure on the procurement and availability of quality ARVs in the south, it was marked by a somewhat questionable philosophy and principles. As Luchini et al. (2003) 
observed, this was fundamentally motivated by what the authors describe as a form of 'political philanthropy', founded on criteria that have had their fair share of criticism. For within the framework of this programme, each pharmaceutical company draws up its own discretionary list of drugs that can be distributed at 'preferential' prices. And it is the company that fixes these preferential prices. This introduces wide discrimination between two groups of countries - which benefit from preferential supplies at different prices - without any clear logic or justification behind this distinction. Furthermore, it is not uncommon, as the organization Médecins Sans Frontières (MSF) has noted in several annual reports (see MSF, 2007), for drugs officially supplied within the framework of ACCESS to be unavailable in practice in the eligible countries, either because the pharmaceutical companies have omitted to request marketing authorization from the national authorities, or quite simply because they do not distribute them.

Nevertheless, competition between originator companies and generic producers, when it has been possible, like the competition between the generic producers themselves, has been highly beneficial, bringing about a substantial improvement in both the price and variety of drugs supplied. In this book, the chapter contributed by Chauveau et al. (Chapter 3) presents a set of original data collected from a panel of Sub-Saharan African countries, demonstrating the full importance of the role played by competition in the price reductions of recent years for ARVs and first-line treatments in this region.

Today, this favourable evolution continues, but it has been impacted by a major WHO initiative to improve quality standards, which is in turn influencing the price and availability of drugs in southern countries.

\section{The Essential and Paradoxical Role of WHO Prequalification}

The introduction of the WHO programme of drug 'prequalification' was an important event in the history of access to treatment. The programme emerged out of particular, almost contingent circumstances. It all started with the launch, in 2001, of a series of generic ARVs, and more especially the fixed-dose combinations (FDCs) supplied by two generic producers, the Indian Cipla and the Thai GPO. As we mentioned above, FDCs constituted an extremely important innovation in terms of treatment, greatly simplifying and alleviating the constraints imposed on patients by the taking of classical tritherapies. These considerations led the WHO to include these in its list of 'essential drugs'.

However, this move raised a serious difficulty. There was no means of verifying the quality and safety of drugs supplied in this generic form. ${ }^{15}$ The WHO found itself in a situation where it was recommending drugs, the quality and safety of which it could not guarantee. 
At the same time, many countries or organizations involved in the distribution of care used or wanted to use these drugs. This was especially the case (along with the large NGO, MSF) for several procurement and distribution agencies, some of which, like UNICEF, belonged to the system of international organizations attached to the UN. Strong pressure was then exerted on the WHO to carry out an activity of certification of the quality of these drugs.

In close consultation with different organizations attached to the United Nations (UNICEF, UNAIDS and UNFPA) and in liaison with the large drug regulation authorities, who were kept regularly informed of its initiative, the WHO set out to develop its response. Finally, in October 2001, the decision was taken and the WHO (acting on behalf of the UN) launched its first 'Expression of Interest' (EI), through the websites of the different UN organizations, aimed at ARV manufacturers. ${ }^{16}$ This was an invitation for drug producers throughout the world to submit dossiers on the drugs for which the WHO proposed to carry out an evaluation of quality and safety. The procedure followed by the WHO covered several dimensions. First, there was an analysis of the quality, harmlessness and efficacy of the drugs, on the basis of the data provided by the manufacturers. If this evaluation was positive, the WHO carried out an inspection of the production sites concerned to verify their conformity with the GMP standards (good manufacturing practices) in force. Only the drugs that successfully passed these tests were then included in the 'list of prequalified drugs' published on the WHO website. In practice, inclusion in the list amounted to obtaining a label of quality guarantee awarded by the organization. ${ }^{17}$

The first list of prequalified drugs was published in March 2002. Since then, it has been regularly updated. In practice, through successive expressions of interest, evaluations and inspections, a growing number of ARVs have obtained prequalification. One particularity of the process worth noting is that it concerns not only the drugs produced by generic firms, but also those produced by the originator, patent-holder companies. Thus, after publication of the most recent list on the organization's website (in February 2008), some 300 different formulations (for AIDS, TB and malaria drugs) are prequalified by the WHO. ${ }^{18}$

For the programme's initiators, the aim was first and foremost to guarantee the quality of drugs procured by UN organizations. However, the initiative soon spread well beyond this context, as the GFTAM and the World Bank decided, in 2002, only to fund the procurement of drugs with a label of quality, awarded either by one of the large Western drug registration authorities or by the WHO. These decisions heralded the end of a much more fluid and flexible situation. Until then, the big international funding agencies (with the notable exception of the Pepfar) showed much more 
flexibility, being prepared to fund the purchase of generics solely by virtue of their reputation or the reputation of the firms supplying them to the market. ${ }^{19}$

This new situation was to have a number of far-ranging consequences. We should start with the positive side, by emphasizing the fact that the WHO prequalification initiative provided a solution to the acute problem of drug safety that had arisen on a global level. The system of prequalification brought a great deal of clarification, creating confidence and establishing a degree of order in a supply of generics whose quality was often not guaranteed by any codified and official process of certification.

But the initiative has also had certain collateral effects on the price and variety of drug supplies. The introduction of the prequalification system has led to a rise in the market price of generics and above all to a contraction in the available supply, itself the result of the removal from the market of a number of products (in principle no longer eligible for the programmes of the international funding organizations) supplied by generic producers for whom investment in the prequalification process cannot be justified. For the most powerful generic firms, obtaining prequalification means entering the exclusive and coveted circle of suppliers to the UN agencies. This explains the commitment of manufacturers (and especially the large generic firms) to the programme. However, for many firms with more limited resources, or for products with a narrow market, engaging in the prequalification process is an expensive and unprofitable exercise. Apart from the costs of upgrading to meet GMP standards, ${ }^{20}$ the main expense is that of bioequivalence. This cost can vary a great deal, usually ranging between US $\$ 10,000$ and US $\$ 100,000$, but it can sometimes be much higher. The decisive factor for generic producers is then the expected sales volume. If this is high, then the costs of bioequivalence can easily be covered. If, on the other hand, the target market is considered to be too narrow, then the investment will be too risky. Added to which, prequalification is, or was in its early days, a slow process, as the resources first allocated to it by the WHO were less than modest.

Ultimately, in terms of the availability and prices of drugs, the programme has had mixed effects. On the one hand, the existence of prequalification increases the competitive pressure on originator firms. By bringing generics into the circle of products prequalified for international funding (UN agencies, World Bank, Global Fund and so on) the WHO programme has unquestionably contributed to the heightening of competitive pressure in this market segment. This effect has been accentuated by the similar Fast-Track initiative of the American FDA (Food and Drug Administration). Shortly after the launch of the WHO prequalification programme, and with the aim of also helping to broaden the supply of 
generics meeting high quality standards, the FDA established its own procedure of qualification for generics. What is more, candidates benefited from an accelerated procedure, known as Fast-Track. In this way, a number of generics have been certified by the FDA. Not only are these drugs, approved by a 'stringent authority', eligible within the framework of funding from the Global Fund, but they are also likely to lighten the Pepfar's budget, which, as noted above, had been the object of sharp criticism from the US Government Accountability Office (2005).

On the other hand, prequalification has resulted in the withdrawal of a number of suppliers from the market, and has thus had a negative influence on price and variety. Indeed, if we compare the price of prequalified drugs with the 'best offers' in terms of price that could be observed before the introduction of prequalification, we can, in certain cases, observe a price increase in the best offer of drugs that are 'eligible' for the programmes of international funding agencies. ${ }^{21}$

It will probably be argued, with good reason, that this 'cost premium', this price difference, represents the 'price of quality' or the 'price of safety'. The cost of quality is certainly an essential element that must be taken into account, and neither the national authorities nor the international funding agencies can take the slightest risk with the quality of drugs simply in order to buy them at a lower price. From the point of view of the efficient use of the public resources that finance the international funding agencies (UN organizations, Global Fund, World Bank), the question is whether and how this 'price of quality' can be brought down, for advances in this domain represent a good that we cannot relinquish. This is the area in which progress needs to be made, and reflection is already under way.

\section{THE RETURN OF DRUG PATENT CONSTRAINTS: THE POST-2005 THREATS ON PUBLIC HEALTH}

The extended deadline imposed on southern countries for TRIPS compliance (1 January 2005), allowed the large generic producers of the south above all India, the only large producer to have benefited fully from this extension to develop a strong generic supply - to supply the world market with low-price ARVs. As we have seen, this phenomenon, coupled in certain cases with preferential offers from originator companies, resulted in big price reductions for the most widely-distributed ARVs.

However, with the end of the extended deadline for TRIPS compliance, the scenario is likely to change radically, especially as regards access to the newer and most efficient drugs. To appreciate the impact that the end of the transition period on 1 January 2005 has had we should first highlight 
the radical transformation brought about, in the domain of public health, by the signing of the TRIPS agreement. By implementing so-called 'minimum standards', the new treaty (signed in 1994) caused a dramatic worldwide upward harmonization and marked a radical break with some of the foundations and rules which had hitherto shaped international intellectual property (IP) protection (UNCTAD-ICTSD, 2005). It introduced two main new 'minimum standards': (i) the patentability of therapeutic molecules became mandatory in all member countries; and (ii) the length of patent protection was extended to 20 years. ${ }^{22}$

Because a transition period was granted to southern countries for compliance with these requirements, the effects of these changes have not been catastrophic. As we have seen, the possibility of competition from generics for most first-line treatments actually resulted in sharp price reductions.

The essential effects of the new period into which we have now entered concern the more recent drugs, which had not been produced in generic form before 2005. In practice, this includes almost all the drugs used in second-line treatments, the consumption of which, already very high, is sure to grow strongly with the passage of time. As we shall see (in Chapters 1 and 2), even if narrow 'windows' can still be exploited to ensure continuity in the supply of generics, the consequences to be expected from the end of transition are of major importance and grave concern.

\section{CONCLUSION}

In this introduction, we have chosen to focus on three essential issues: the funding made available for public health programmes, the supply of drugs, in terms of price and variety, and the impact of international IP agreements on the future supply and availability of treatments in the developing countries.

We believe these to be questions of key importance, but many other problems and difficulties remain to be overcome on the road to the provision of universal free access that has now been adopted as the objective of the community of players engaged in the fight against the AIDS pandemic. The questions we have singled out in this introduction are no more than peaks emerging from a sea of problems. In its own way, each of the chapters in this book, while underlining the successes achieved, seeks to shed more light on different aspects of the complex landscape of the fight against AIDS in the southern countries today. 


\section{OUTLINE OF THE BOOK}

The aim of this introduction has been simply to outline some of the key features of the new era into which we have moved in the fight to provide access to care. It only remains for us to describe how the book has been organized, with the aim of contributing to a greater understanding of the challenges represented by the objective of providing universal access for PLWHA in need.

- Part I, 'TRIPS, generic drugs and access to care: the post-2005 issues', is dedicated to a presentation of the new legal frame now in force and an analysis of the multiple constraints it imposes. This presentation of the legal context is completed by a detailed study of the main 'TRIPS-plus' agreements signed to date, and which constitute, for the future, even harsher constraints than TRIPS. The part ends with a study of the major role played by generic producers in bringing down prices, a means of recalling their importance up until now and our need, in the present situation, to ensure that they can continue to play their full role in the future.

- Part II, 'Securing free and universal access: lessons from Brazil', revisits the Brazilian experience to see what lessons can be drawn from this key episode. Brazil represents the first and so far the most important success in the implementation of a programme of universal and free access. With the benefit of hindsight, the chapters in this part assess the way in which the country's remarkable successes were achieved. The difficulties encountered along the way, the shortcomings, and the threats hanging over the programme's future are also given their full importance.

- Part III, 'Fighting AIDS in the heart of the pandemic: Sub-Saharan and low-income countries', in presenting works devoted to different aspects of the fight against the epidemic, gives a measure of the scale and complexity of the problems facing the many different actors engaged in local programmes of action against AIDS. It is here, in the African sub-continent, that the essential battle is being fought. It is here that it will be won or lost. Although it would be impossible for them to cover the whole picture, the chapters in this part bring to light the crucial features of the difficulties facing the fight against AIDS in this region.

- Part IV, 'Building the future: public health systems and the free access challenge', looks more towards the future. It focuses on two issues that will be decisive in the fight against AIDS: the improvement of health systems and the introduction of free care. These two 
questions go hand in hand, for, as several recent studies have shown, it is only by advancing on both fronts that significant progress can be made in the future.

I shall conclude on a more personal note, but which is more than just that. I would like to take this opportunity to pay tribute to the ANRS, and to all its teams, for the many years of remarkable work they have devoted to supporting social science research into AIDS, research which could never have been conducted without them. All the chapters in this book stem directly from research financed and often largely supported by the ANRS. Without the ANRS, in other words, this book would never have seen the light of day. A word of thanks also to all the authors, who submitted with such good grace to the many demands imposed on them during their participation in this work. Many thanks as well to Richard Crabtree for translating or re-editing all chapters of this volume and also to Magali Amougou who helped me with the preparation of the manuscript.

It remains for me to hope that in the hands of its readers, this book will now play its role. My wish is that, by helping to nurture discussion and exchange, by leading to a better understanding of the problems to be overcome in the fight against AIDS, it will contribute to further progress, to fresh advances.

\section{NOTES}

1. See Chapter 9, where this important question is presented and discussed.

2. Two essential moments in this movement towards the objective of universal access should be noted. The first was the Declaration of Commitments on HIV/AIDS of June 2001, agreed by the Heads and Representatives of WHO member countries. The second, of a completely different nature, was the launch of the ' $3 \times 5$ ' initiative by the WHO towards the end of 2004. This was a move by the WHO to encourage the strong growth and acceleration of programmes by issuing a series of recommendations and guidelines with the aim of ensuring ART for 3 million patients by the end of 2005. Unsurprisingly, this target was not actually reached (it is estimated that only 1.3 million people were receiving ART at the end of 2005), but the initiative made a big splash, and contributed greatly to the upsurge in programmes.

3. This obviously crucial aspect, dauntingly complicated to put into practice, is examined in Chapters 13 and 14 of this book. The introduction to Part IV provides several essential points of reference on this.

4. These estimates, produced by the big international organizations, are the most reliable available. Nevertheless, much remains to be done to refine the statistical apparatus and models on which these estimates are based. These tricky questions and their implications are discussed in Chapter 8 of this book, with regard to Sub-Saharan Africa.

5. In this sense, it extends and updates the results already obtained in this domain through the research funded by the ANRS, presented in Moatti et al. (2003).

6. The TRP is a key institution of the Global Fund. It assesses the projects submitted, and funding decisions are taken on the basis of its recommendations. 
7. Data drawn from the 'Monthly Progress Update - 31 October 2007', available at www.theglobalfund.org.

8. There have been six proposals rounds, with board approval of accepted proposals given in April 2002, January 2003, June 2004, September/December 2005 and November 2006. Round 7 proposals are currently being reviewed by the TRP and will be voted on by the board in November 2007. Round 8 was launched on 1 March 2008.

9. Chapter 11 of this book provides illustrations of the difficulties that arise for the local actors out of this plurality of rules and constraints when funding from several sources comes together in one country.

10. All the more so since, in addition to the 'big three' we have just briefly described, there have been a large number of private donors and bilateral or multilateral programmes containing, in varying proportions, grants for the fight against AIDS. The Bill Gates Foundation is the most recent, but is already making its presence felt in many programmes.

11. See Chapter 12 in this book, which presents these new public health approaches initiated by the WHO.

12. First-line treatments are administered to new patients, before the development of any drug resistance in the virus, which would then require switching to a second-line treatment.

13. During the same period, another generic producer in Thailand, the public laboratory GPO, introduced another tritherapy as an FDC (fixed-dose combination). However, this was distributed less widely than the Indian FDC.

14. The ACCESS program (also known as the Accelerating Access Initiative) is an initiative launched in early 2000. Under the aegis of major international organizations (the United Nations Population Fund, UNICEF, the World Health Organization, the World Bank and UNAIDS) a partnership was set up with large pharmaceutical companies (Boehringer, BMS, GlaxoSmithKline, Merck, Roche, later joined by Abbott) with the aim of offering access to treatment to the least developed countries. Within this framework, and using a classification based on the indicator of human development, countries classified as the 'least developed countries' are eligible for a significant reduction in the price of ARVs. However each pharmaceutical company sets the restrictions of eligibility for countries, determining on a case-by-case basis the nature and the price of the drugs offered. These idiosyncratic distinctions account for the large price discrepancies observed for the same drug in different countries (see below). For more details on this issue, see Luchini et al. (2003).

15. There were two reasons for this. First, because these drugs incorporated active ingredients (APIs) and substances patented in the north. As such, they could not be registered in northern countries and could not, therefore, be subjected to the quality tests required for registration. Second, as these drugs were new, there were no specifications for them in existing Pharmacopoeia to enable their quality and safety to be evaluated.

16. A second EI quickly followed, in August 2002. New ones have regularly been issued since then.

17. Note that the WHO reserves the right to carry out random checks on the prequalified drugs and their production sites to verify their continuing quality and safety standards.

18. This list also includes patented and generic drugs registered with the FDA under its 'Fast-Track' procedure (see below).

19. This is the case, for example, for the GTB (Global Tuberculosis Programme), whose suppliers include generic producers whose products have not undergone bioequivalence tests.

20. Which can be very high if new production lines need to be installed.

21. To our knowledge, no systematic survey of this point has been made. However, from data collected and presented by MSF (2007), significant differences can be observed in many cases between the 'best offer' of an ARV and the 'best offer' for the same class of ARV having been prequalified by WHO authorities. Thus, for example, the relative prices for best prequalified offer and best offer are \$28 compared with \$20 for D4T (30mg capsules), \$134 compared with \$128 for the 3TC/AZT combination, \$231 
compared with \$194 for the FDC AZT/3TCNVP and so on. Above all, this document shows that for many of the ARVs and FDCs used, there are quite simply no prequalified formulations. It is also in this case that the price differences between generic and patented products are the largest: \$400 compared with \$321 for IDV, \$678 compared with \$256 for the FDC ABC/3TC, \$319 compared with \$274 for the FDC TDF/FTC and so on. And we should specify that the 'best offer' for patented drugs presented here is the price proposed only to low-income countries, and it is therefore not available to 'intermediate' countries.

22. This paragraph and the ones that follow draw on arguments already presented in Orsi et al. (2007).

\section{BIBLIOGRAPHY, REFERENCES AND OTHER SOURCES}

Bernstein M. and M. Sessions (2007), 'A Trickle or a Flood, Commitments and Disbursement for HIV/AIDS from the Global Fund, PEPFAR and the World Bank's MAP', Center for Global Development, HIV/AIDS Monitor, 5 March.

Luchini, S., B. Cisse, S. Duran and J.-P. Moatti (2003), 'Decrease in Prices of Antiretroviral Drugs for Developing Countries: From Political "Philanthropy" to Regulated Markets?', in J.P. Moatti, B. Coriat, Y. Souteyrand et al. (eds), Economics of AIDS and Access to HIVIAIDS Care in Developing Countries. Issues and Challenges, Paris: Editions de l'ANRS, pp. 169-211.

Médecins Sans Frontières (2007), 'Untangling the Web of Price Reductions: A Pricing Guide for Purchase of ARTs for Developing Countries, 10th Edition', available at http://www.accessmed-msf.org/documents/untanglingteweb $\% 209$. pdf.

Moatti, J.P., B. Coriat, Barnett T. Souteyrand, J. Dumoilin and Y.A. Flori (eds) (2003), Economics of AIDS and Access to HIVIAIDS Care in Developing Countries - Issues and Challenges, Paris: Editions ANRS.

Orsi, F., C. d'Almeida, L. Hasenclever, M. Camara, P. Tigre and B. Coriat (2007), 'TRIPS post-2005 and Access to New Antiretroviral Treatments in Southern Countries: Issues and Challenges', AIDS, 21(15), 1997-2003

Scherer F.M. (1993), 'Pricing, Profits and Technological Progress in the Pharmaceutical Industry', Journal of Economic Perspectives, 7(3): 97-115.

UNAIDS (2006), 'Political Declaration on HIV/AIDS, Resolution Adopted by the General Assembly at the 87th Plenary Meeting', available at http://data. unaids.org/pub/Report/2006/20060615_HLM_PoliticalDeclaration_ARES6026 2_en.pdf.

UNAIDS and World Health Organization (2006), 'Aids Epidemic Update: December', available at http://data.unaids.org/pub/EpiReport/2006/2006_ Epi Update_en.pdf.

UNAIDS, World Health Organization (2007), Aids epidemic estimate, http://data. unaids.org.pdf.

UNCTAD-ICTSD (2005), Resource Book on TRIPS and Development, New York: Cambridge University Press.

United Nations (2001), 'Declaration of Commitments on HIV/AIDS', General Assembly Special Session on HIV/AIDS, 25-27 June, available at http://data. unaids.org/publications/irc-pub03/aidsdeclaration_en.pdf. 
US Government Accountability Office (2005), 'Global HIV/AIDS Epidemic, Selection of Antiretroviral Medications Provided under the US Emergency Plan is Limited'.

World Health Organization (2006), 'Antiretroviral Therapy for HIV Infection in Adults and Adolescents: Recommendations for a Public Health Approach', Revision, available at http://www.who.int/hiv/pub/guidelines/artadultguidelines. pdf.

World Health Organization, UNAIDS, UNICEF (2007), 'Towards Universal Access: Scaling-Up Priority HIV/AIDS Interventions in the Health Sector: Progress Report', available at http://data.unaids.org/pub/Report/2007/20070925_ oms_progress_report_en.pdf.

World Health Organization (2007), 'Global Price Reporting Mechanism', available at http://www.who.int/hiv/amds/gprm/en/index.html. 
Benjamin Coriat - 9781848444898 Downloaded from PubFactory at 04/26/2023 01:23:34AM via free access 